\title{
Article
}

\section{SOX2OT Long Noncoding RNA Is Regulated by the UPR in Oestrogen Receptor-Positive Breast Cancer}

\author{
Carole Ferraro-Peyret ${ }^{1,2,3, *}$, Marjan E. Askarian-Amiri ${ }^{1,4} \oplus$, Debina Sarkar ${ }^{1,4,5} \oplus$, Wayne R. Joseph ${ }^{1}$, \\ Herah Hansji ${ }^{1,4,6}$, Bruce C. Baguley ${ }^{1}$ (1) and Euphemia Y. Leung ${ }^{1,4, * \mathbb{C}}$
}

1 Auckland Cancer Society Research Centre, University of Auckland, 85 Park Rd, Grafton, Auckland 1023, New Zealand; marjan.askarianamiri@gmail.com (M.E.A.-A.); debina.sarkar@otago.ac.nz (D.S.); w.joseph@auckland.ac.nz (W.R.J.); herah.hansji@mcri.edu.au (H.H.); b.baguley@auckland.ac.nz (B.C.B.)

2 Univ Lyon, ISPB Faculty of Pharmacy, INSERM 1052, CNRS5286, Cancer Research Centre of Lyon, F-69008 Lyon, France

3 Hospices Civils de Lyon, Biopathology of Tumours, GHE Hospital, F-69500 Bron, France

4 Molecular Medicine and Pathology Department, University of Auckland, 85 Park Rd, Grafton, Auckland 1023, New Zealand

5 Biochemistry Department, University of Otago, 710 Cumberland Street, Dunedin North, Dunedin 9016, New Zealand

6 Murdoch Children's Research Institute, The Royal Children's Hospital, Flemington Rd, Parkville, VIC 3052, Australia

* Correspondence: carole.ferraro-peyret@univ-lyon1.fr (C.F.-P.); e.leung@auckland.ac.nz (E.Y.L.)

check for updates

Citation: Ferraro-Peyret, C.; Askarian-Amiri, M.E.; Sarkar, D.; Joseph, W.R.; Hansji, H.; Baguley, B.C.; Leung, E.Y. SOX2OT Long Noncoding RNA Is Regulated by the UPR in Oestrogen Receptor-Positive Breast Cancer. Sci 2021, 3, 26 https://doi.org/10.3390/sci3020026

Academic Editors: Aamir Ahmad and Tomoharu Sugie

Received: 6 March 2020

Accepted: 20 March 2020

Published: 26 May 2021

Publisher's Note: MDPI stays neutral with regard to jurisdictional claims in published maps and institutional affiliations.

Copyright: (c) 2021 by the authors. Licensee MDPI, Basel, Switzerland This article is an open access article distributed under the terms and conditions of the Creative Commons Attribution (CC BY) license (https:// creativecommons.org/licenses/by/ $4.0 /)$

\begin{abstract}
Endoplasmic reticulum (ENR) stress perturbs cell homeostasis and induces the unfolded protein response (UPR). In breast cancer, this process is activated by oestrogen deprivation and is associated with tamoxifen resistance. We present evidence that the transcription factor SOX2 and the long noncoding RNA SOX2 overlapping transcript (SOX2OT) are upregulated in oestrogen receptor-positive $(\mathrm{ER}+)$ breast cancer and in response to oestrogen deprivation. We examined the effect of the UPR on SOX2 and SOX2OT expression and the effect of SOX2OT on UPR pathways in breast cancer cell lines. The induction of the UPR by thapsigargin or glucose deprivation upregulates SOX2OT expression. This upregulation is also shown with the anti-oestrogen $4 \mathrm{OH}$-tamoxifen and mTOR inhibitor everolimus in ER + breast cancer cells that are sensitive to oestrogen deprivation or everolimus treatment. SOX2OT overexpression decreased BiP and PERK expression. This effect of SOX2OT overexpression was confirmed on BiP and PERK pathway by q-PCR. Our results show that a long noncoding RNA regulates the UPR and evince a new function of SOX2OT as a participant of ENR stress reprogramming of breast cancer cells.
\end{abstract}

Keywords: breast cancer; LncRNA; SOX2OT; SOX2; UPR; 4-OH tamoxifen

\section{Introduction}

Despite extensive studies in breast cancer and more detailed knowledge of its molecular pathways, many aspects of breast cancer cell regulation are still enigmatic. Recent genomic and transcriptomic analyses showed that most of the transcripts are long noncoding RNAs (lncRNAs), and evidence for regulatory roles for lncRNAs continues to rise. The dysregulation of several lncRNAs in breast cancer has been reported [1-3] and the functions of this class of transcript require elucidation. Within an intronic region of the gene specifying the SOX2 overlapping transcript (SOX2OT) lncRNA lies the SOX2 gene, one of the main regulators of pluripotency (Figure 1, [4]). As described previously [4], SOX2 and SOX2OT are differentially expressed in ER+ and ER- breast cancer. They are both upregulated in suspension culture under conditions that prioritise spheroid formation. Hence, we suggest that in breast cancer, SOX2OT is key to the regulation of SOX2 expression. However, the mechanism of action of SOX2OT in breast cancer remains to be 
fully defined. Expression analysis of murine Sox2 and Sox2OT in different developmental systems has also elucidated the dynamically changing expression patterns of these two RNA species and has suggested important roles for these genes in normal development [5].

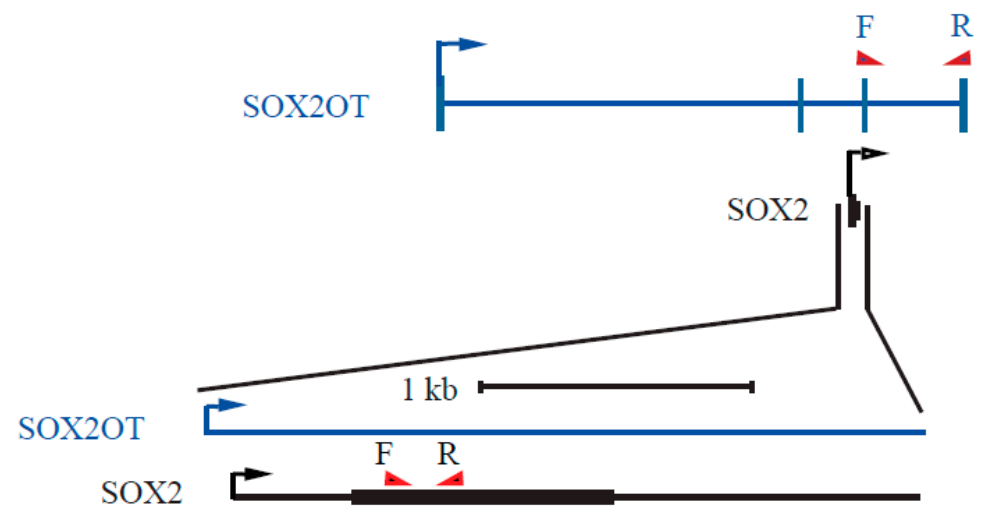

Figure 1. Schematic of the SOX2 and SOXOT genes. The SOX2 gene lies in an intronic region of the SOX2 Overlapping Transcript gene (SOX2OT). The direction of the transcription is shown with arrows. The triangles above each gene show the forward $(\mathbf{F})$ and reverse $(\mathbf{R})$ primers used in PCR. The SOX2 gene is enlarged.

The dysregulation of SOX2OT and SOX2 expression has also been shown in cancers such as glioma and kidney carcinoma [5], and significant correlations in expression of these two genes were found in breast cancer [4], as well as in oesophageal [6] and lung squamous cell carcinoma [7-9]. We have previously shown in breast cancer that the differential expression of SOX2 and SOX2OT is oestrogen receptor dependent. SOX2OT and SOX2 are more highly expressed in oestrogen receptor-positive (ER+) than in ER-negative (ER-) breast cancer cell lines [4]. Interestingly, high expression levels of SOX2OT and SOX2 are associated with the sensitivity of breast cancer cells to tamoxifen [4]. To investigate the mechanism of action of SOX2OT in breast cancer further, we have examined the role of the unfolded protein response (UPR) pathway in the expression of this lncRNA.

Multiple mechanisms have been described for tamoxifen resistance to breast cancer. One of those pathways is known as the unfolded protein response (UPR). Three endoplasmic reticulum (ENR) stress transducers defining three distinct axes of the UPR have been identified so far and characterised as components of the UPR activation pathway (Figure 2). IRE1, PERK, and ATF6 are the three transmembrane inducers of ENR stress [10]. These three regulators of UPR are controlled by the ENR chaperone BiP, constitutively bound to them but dissociated under ENR stress. The UPR transiently inhibits protein synthesis and induces the production of chaperone molecules in order to restore ENR homeostasis and promote cell survival [11]. The failure of this rescue mechanism results in apoptotic cell death [12].

UPR activation is associated with poor prognosis in breast cancer [13,14]. Breast cancer cells of all subtypes have elevated UPR signalling with elevated BiP expression $[15,16]$. The UPR may favour oestrogen-dependent breast cancer survival when oestrogen availability is low [17-19]. The IRE-1 pathway is activated in ER+ breast cancer: it induces the splicing of XBP1 mRNA, consequently increasing the abundance of its pro-survival target XBP1s, which are strongly correlated with ER alpha expression in breast cancer [14,20]. It has been shown that silencing of XBP1, or inhibition of IRE1 by the pharmacological inhibitor STF80310 or MKC 866, reverses resistance to anti-oestrogen therapies [21-23]. XBP1s expression promotes the survival of triple-negative breast cancer (TNBC) cells [24]. Finally, the PERK pathway is activated in breast cancer cells resistant to tamoxifen [20,21,25].

The ability of the UPR to regulate gene expression and protein synthesis and its contribution to oncogenesis have been well documented. Recent results have shown that the UPR can regulate post-transcriptional networks either by regulated IRE1-dependent decay (RIDD) of selected mRNAs [26] or by modulation of expression of micro-RNAs [27]. The 
UPR can also suppress the expression of several miRNAs that regulate either the PERK or the IRE1 pathway. However, an added layer of regulatory complexity that entails the role of lncRNA in the UPR pathway has been barely explored. Here, we investigate the gene expression pattern of SOX2OT in a UPR-induced system. Our results show that SOX2OT expression can be upregulated by ENR stress inducers and that this IncRNA can also downregulate the PERK pathway and BiP expression in ER+ breast cancer cell lines.

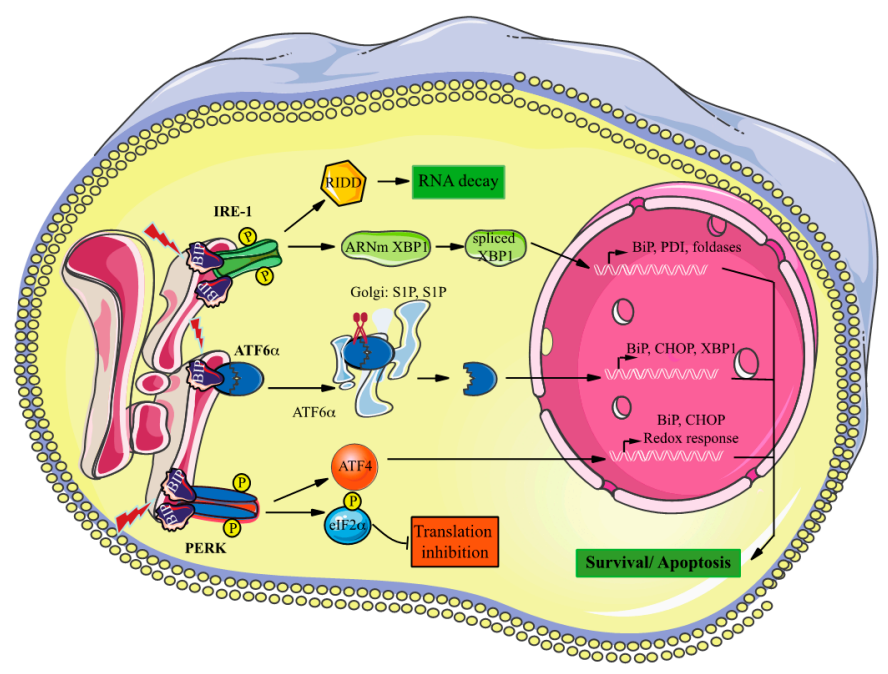

Figure 2. Schematic of pathways involved in the UPR.

\section{Material and Methods}

\subsection{Cell Lines}

As previously described, the MCF-7 and MDA-MB-231 cell lines were purchased from the ATCC, grown in alpha-MEM containing 5\% foetal calf serum (FCS), penicillin/streptomycin (100 U/mL and $100 \mu \mathrm{g} / \mathrm{mL}$, respectively), and insulin/transferrin/selenium supplement (Roche). Long-term oestrogen-deprived sublines TamC3 and TamC6 were generated by growing the MCF-7 cells in oestrogen-deprived medium (phenol red-free RPMI 1640 (GIBCO) with 5\% charcoal-stripped foetal bovine serum) and penicillin/streptomycin $(10 \mathrm{U} / \mathrm{mL}$ and $10 \mu \mathrm{g} / \mathrm{mL})$, for 10 months, [28-31]. The T47D cell line was purchased from the ATCC, grown in alpha-MEM containing $5 \%$ foetal calf serum (FCS) and penicillin/streptomycin $(100 \mathrm{U} / \mathrm{mL}$ and $100 \mu \mathrm{g} / \mathrm{mL})$.

For glucose depletion, cells were seeded in six-well plates and maintained $48 \mathrm{~h}$ under normal culture conditions, i.e., $25 \mathrm{mM}$ glucose concentration, $5 \% \mathrm{FCS}, 5 \% \mathrm{CO}_{2}, 21 \%$ $\mathrm{O}_{2}$. The medium was replaced with no glucose DMEM (GIBCO) containing 5\% FCS, penicillin/streptomycin $(100 \mathrm{U} / \mathrm{mL}$ and $100 \mu \mathrm{g} / \mathrm{mL})$, and insulin/transferrin/selenium supplement (Roche).

\subsection{Reagents}

Thapsigargin was obtained from Applichem (St. Louis, MO, USA), Everolimus from Selleck Chemicals (Houston, TX, USA), and 4-OH Tamoxifen is from Sigma-Aldrich (St. Louis, MO, USA). Anti-PERK (No. 3192) antibody was purchased from Cell Signaling Technology (Beverly, MA, USA). Anti-BIP antibody (610978) was from BD Laboratories ${ }^{\mathrm{TM}}$ (Franklin Lakes, NJ, USA). Antibody against $\alpha$-tubulin was from Sigma-Aldrich (St. Louis, MO, USA).

\subsection{Protein Extraction and Western Blot Analysis}

As described in detail previously [29], breast cancer cell lines were grown to log-phase, washed twice with ice-cold PBS, and lysed in SDS lysis buffer according to the manufacturer's protocol (Cell Signalling Technology, Danvers, MA, USA). Protein concentration was quantified using the bicinchoninic acid reagent (Sigma). Cell lysates containing $20 \mu \mathrm{g}$ 
of protein were separated by electrophoresis on a 4-10\% SDS-PAGE gel (Life Technologies) and transferred to a polyvinylidenedifluoride membrane (PVDF) (Millipore, Billerica, MA USA). Blocking of nonspecific binding was achieved in a $0.1 \%$ Tween 20 Tris-buffered saline solution containing $5 \% w / v$ non-fat dry milk powder for $1 \mathrm{~h}$. Membranes were incubated with primary antibodies overnight at $4{ }^{\circ} \mathrm{C}$, washed, and incubated with the corresponding immunoperoxidase-conjugated secondary antibody (Santa Cruz Biotechnology) for $1 \mathrm{~h}$ at room temperature. Bound antibody was visualised using SuperSignal West Pico (Thermo Scientific, Waltham, MA, USA) or ECL Select (Amersham) and the chemiluminescence detection system by Fujifilm Las-3000.

\subsection{Reverse Transcription, $c D N A$ Synthesis, and Quantitative PCR and PCR}

As described in detail previously [4], oligo-dT and random primers were used to reverse transcribe RNA with qScript Flex cDNA kit (Dnature) according to the manufacturer's instructions. For RT-qPCR analysis, qPCR was performed using gene-specific primers (Supplementary Materials Table S1) and Sybr Green MasterMix (Life Technologies), and expression values normalised relative to GAPDH and HPRT mRNA expression.

\subsection{Ectopic Expression of SOX2 and SOX2OT}

This has been described in detail previously [4]. Constructs overexpressing SOX2 (NM_003106) and SOX2OT (NR_004053) and control empty plasmid (vector), Ex-NEGM95, and EX-hLUC-M90, respectively, were purchased from GeneCopoeia. Both plasmids express SV40-mCherry-IRES-puromycin resistance, allowing detection of transfected cells. Breast cancer cells (MDA-MB-231) were chosen because of the low expression of SOX2OT and SOX2 as we have previously shown [4]. The cells were transfected with $5 \mu \mathrm{g}$ of DNA and Lipofectamine Plus (Invitrogen) according to the manufacturer's instructions. Three biological replicates for each construct were made, the transfected cells treated with puromycin and selected on the basis of mCherry expression by fluorescence-activated cell sorting (FACS), as previously described [4]. The sorted cells were maintained in the presence of puromycin.

\subsection{Statistical Analysis}

Results are presented as mean \pm SEM. As described in detail previously [4], t-tests or Mann-Whitney rank sum tests were used for comparison between two groups. Correlation analysis was performed with Spearman's rank correlation coefficient $(\mathrm{R})$ and statistical significance $(p)$ using SigmaPlot. $p<0.05\left(^{*}\right), p<0.01\left(^{* *}\right)$ or $p<0.001\left(^{* * *}\right)$ were indications of statistical significance.

\section{Results}

\subsection{Relationship between Expression of SOX2OT and ENR STRESS Stress-Inducible Genes in} Breast Cancer

SOX2OT and SOX2 transcripts are upregulated in tamoxifen-resistant cell lines $[4,32]$. The activation of the UPR in ER+ breast cancer cell lines following tamoxifen treatment has also been shown previously [33-35]. We initially analysed the genome wide-RNA transcript profile of breast cancer samples from the Cancer Genome Atlas (TCGA) by RNAseq dataset (TGCA8BRCA_exp_HiSeqV2-2015-02-24-160222) including 1025 samples from breast cancer patients. Interestingly, we found different patterns of expression of UPR-inducible genes relative to SOX2OT but not SOX2 (Figure 3). As shown in Table 1, the expression of XBP1 and SOX2OT were positively correlated (Spearman's correlation coefficient $r=0.355$, $p=2.0 \times 10^{-7}$ ). This analysis showed no correlation between the expression of BiP and SOX2OT while the expression of the other genes examined was negatively correlated with that of SOX2OT, with a weak correlation. However, we found no correlation of ER stress-inducible genes with SOX2 with the exception of PDIA4 $\left(r=0.92, p=1.4 \times 10^{-3}\right)$. 


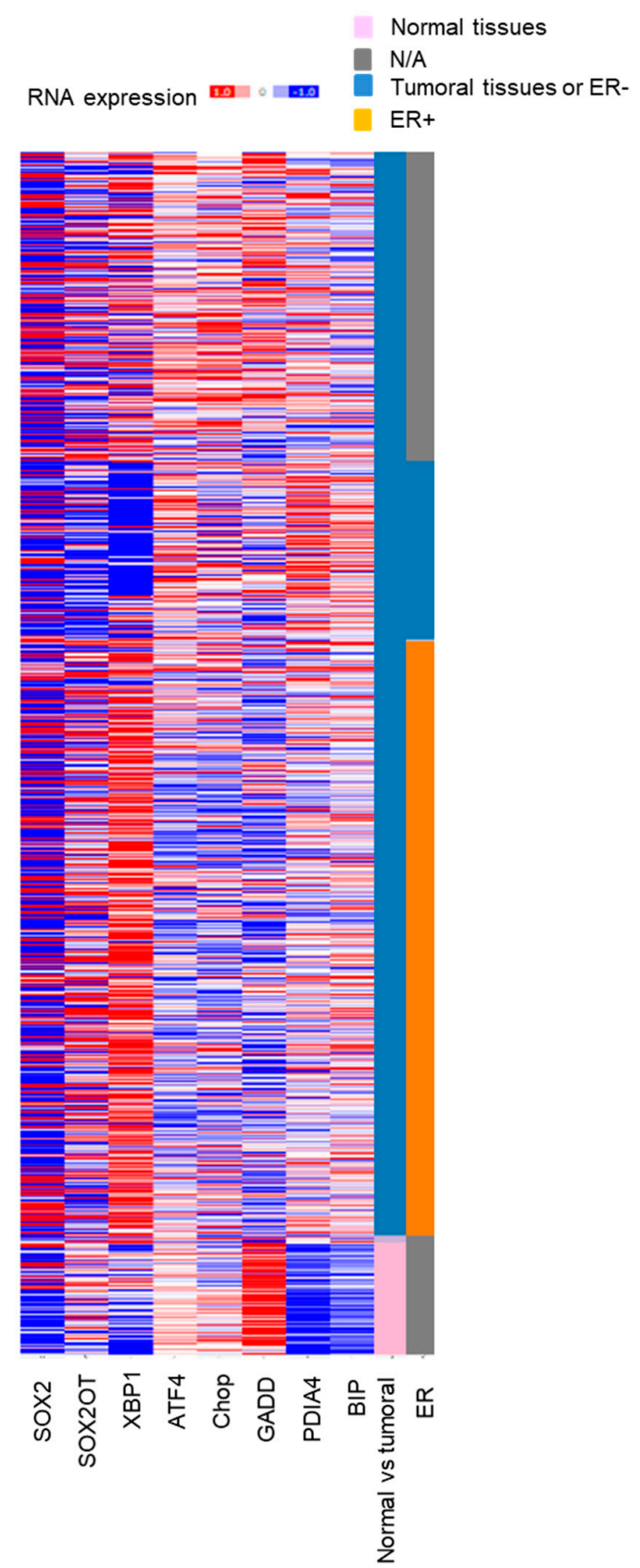

Figure 3. Heat map showing the expression of SOX2, SOX2OT, and UPR-related genes. It shows the expression of genes in the PERK pathway (ATF4, CHOP/ddit3, GADD/pp1r15a), ENR-associated degradation (BiP/hspa5, PDIA4), and the IRE1 pathway (XBP1) in breast cancer samples. Data were from TCGA invasive breast carcinoma (TGCA8BRCA_exp_HiSeqV2-2015-02-24-160222). The samples were classified based on their receptor status (oestrogen receptor (ER), HER2, or progesterone receptor (PR)).

Table 1. Spearman correlation coefficients of relative gene expression for SOX2OT and SOX2 compared to the expression of genes of the UPR pathways in TGCA samples $(n=1025)$.

\begin{tabular}{ccccccc}
\hline & ATF4 & CHOP & GADD & PDIA4 & XBP1 & BiP \\
\hline SOX2OT & -0.195 & -0.167 & -0.148 & -0.171 & 0.355 & 0.019 \\
$p$ value & $7.26 \times 10^{-12}$ & $4.95 \times 10^{-9}$ & $2.25 \times 10^{-7}$ & $1.92 \times 10^{-9}$ & $2.00 \times 10^{-7}$ & 0.508 \\
SOX2 & 0.00381 & 0.0744 & -0.0549 & 0.0918 & 0.0158 & 0.0311 \\
$p$ value & 0.894 & $9.48 \times 10^{-3}$ & 0.848 & $1.36 \times 10^{-3}$ & 0.581 & 0.278 \\
\hline
\end{tabular}




\subsection{SOX2OT Expression Is Upregulated in ER + Stressed Cells}

To investigate whether IncRNA SOX2OT or SOX2 is differentially expressed by ENR stress, two breast cancer cell lines (MCF-7 and T47D) were treated with the UPR inducer thapsigargin (Tg). We also studied the effect of two other drugs used to treat ER+ breast cancer cells: the anti-oestrogen $4 \mathrm{OH}-\mathrm{Tam}$ and the mTOR inhibitor everolimus, both of which have been shown to induce the UPR in breast cancer cell lines [36] and in MCF-7 and T47D (Supplementary Materials Figure S1). Cells were assessed for PERK phosphorylation and BiP induction as markers of UPR activation using Western blot analysis (Supplementary Data S1). After 16h of treatment with $\mathrm{Tg}$, a significant upregulation of SOX2OT expression was detected in both cell lines $(9.3 \pm 2.26$ fold in MCF-7 cells and $3.8 \pm 0.96$ fold in T47D cells) (Figure 4). This induction was also observed for SOX2 expression in both cell lines. Treatment with 4OH-Tam and everolimus also upregulated SOX2OT in MCF-7 cells, while everolimus significantly induced SOX2OT in T47D cells. The SOX2 level was significantly upregulated in MCF-7 and T47D cells treated with Tg or 4OH-Tam but not with everolimus.

A

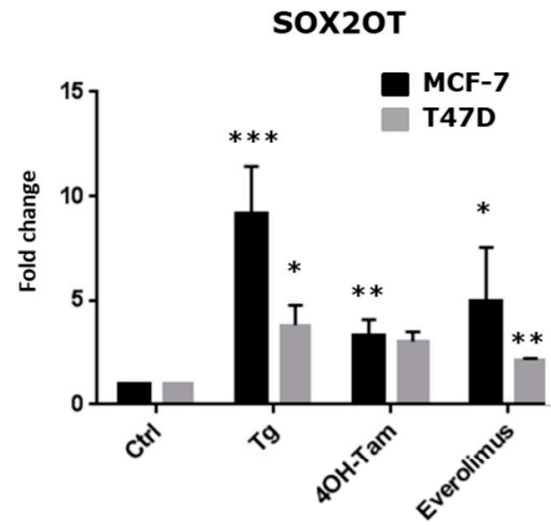

C

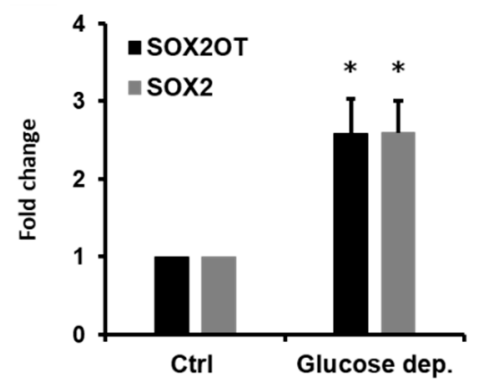

B

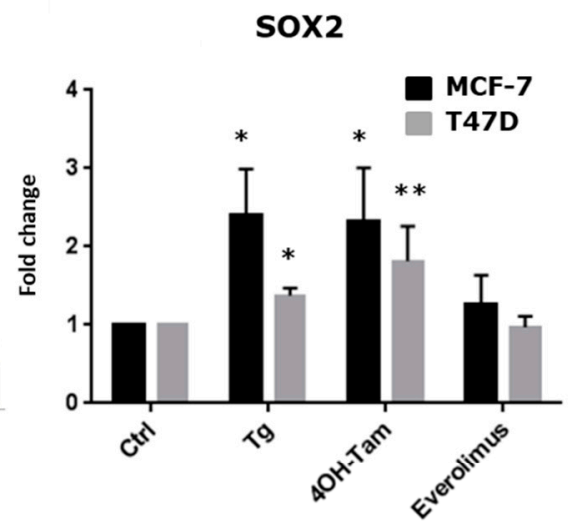

Figure 4. Expression of SOX2OT and SOX2 following UPR induction in ER+ breast cancer cell lines. MCF-7 and T47D cells were incubated in a control medium (Ctrl) or in a medium containing the ER stress-inducing agents thapsigargin $(\mathrm{Tg}, 300 \mathrm{nM}), 4 \mathrm{OH}-\mathrm{Tam}(0.1 \mu \mathrm{M})$, or everolimus $(10 \mathrm{nM})$ for $16 \mathrm{~h}$. $(\mathbf{A}, \mathbf{B})$ : The effects of $\mathrm{Tg}, 4 \mathrm{OH}-\mathrm{Tam}$, and everolimus on the expression of SOX2OT and SOX2 were measured by RT-qPCR and are relative to the housekeeping genes HPRT and GAPDH. (C): MCF-7 cells were cultivated in media containing $25 \mathrm{mM}$ glucose (Ctrl) or lacking glucose (Glucose dep) for $48 \mathrm{~h}$. The expression of SOX2OT and SOX2 was measured by RT-qPCR and is relative to HPRT and $G A P D H$. Error bars represent standard deviations of at least 3 independent experiments. ${ }^{*} p<0.05$, ${ }^{* *} p<0.01,{ }^{* * *} p<0.001$.

MCF-7 cells were also grown under conditions of glucose deprivation, an intrinsic inducer of the UPR. After $48 \mathrm{~h}$ of cultivation in glucose-depleted medium, significant increases in the expression of SOX2OT and SOX2 were detected (Figure 4C).

As the UPR is upregulated in tamoxifen-resistant cells, we analysed the effects of $\mathrm{Tg}, 4 \mathrm{OH}-\mathrm{Tam}$, and everolimus in two oestrogen-deprived and -resistant breast cancer cell lines derived from MCF-7 cells: TamC3 and TamC6 [28-31]. We have previously shown 
that the sensitivity to mTOR inhibition of these two cell lines is different: TamC6 cells are highly sensitive to everolimus, as compared to TamC3 cells [29-31]). Here, we show that Tg upregulated the expression of SOX2OT in both cell lines, while SOX2 is upregulated only in the TamC6 cell line (Figure 5). 4OH-Tam did not induce the expression of these genes in TamC6 cells, whereas in TamC3 SOX2OT expression was increased (Figure 5). Everolimus, on the other hand, induced a significant increase of SOX2OT expression in TamC6 cells but not in TamC3 cells, while SOX2 was upregulated by everolimus in both cell lines.
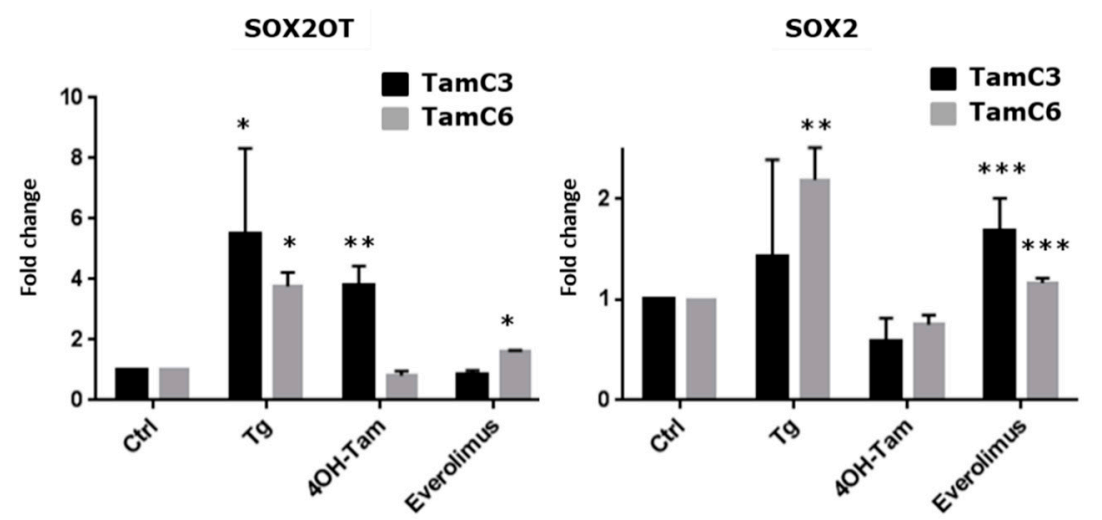

Figure 5. Expression of SOX2OT and SOX2 following UPR induction in oestrogen-deprived cancer cells. TamC3 and TamC6 were incubated in a control medium (Ctrl) or in a medium containing the ENR stress-inducing agents thapsigargin $(\mathrm{Tg}, 300 \mathrm{nM}), 4 \mathrm{OH}$-Tam $(0.1 \mu \mathrm{M})$, or everolimus $(10 \mathrm{nM})$ for 16h. The expression of SOX2OT and SOX2 was measured by RT-qPCR and is relative to that of HPRT and GAPDH. Error bars represent standard deviations of three independent experiments. ${ }^{*} p<0.05$, ** $p<0.01,{ }^{* * *} p<0.001$.

\subsection{SOX2OT, but Not SOX2, Regulates BiP Expression and PERK Activation}

To study further the role of the SOX2OT transcript in the UPR in breast cancer, we used the MDA-MB-231 cell line, which has low expression of SOX2OT, and in which we had induced ectopic expression of SOX2OT lncRNA [4]. The activation of the UPR pathway in cells overexpressing either SOX2OT or SOX2 was studied at a transcriptional level, quantifying BiP and the PERK targets ATF4 and CHOP by RT-qPCR. When SOX2OT was overexpressed, BiP and CHOP expression was significantly reduced, to $50 \%$ of control values (Figure 6A), while XBP1s mRNA expression was not significantly changed (Figure 6B). However, in SOX2 overexpressing cells ATF4 was upregulated, while CHOP and $\mathrm{BiP}$ showed no significant change (Figure 6A). XBP1s mRNA was quantified by RTqPCR and was not modified by SOX2 overexpression (Figure 6B). We further investigated whether SOX2OT could inhibit BiP and the PERK by Western blot analysis for BiP and PERK expression. Our results show that the expression of BiP and PERK decreased in SOX2OT overexpressing cells (Figure 6C).

A positive correlation for the expression of SOX2OT and SOX2 has been reported [4,5]. Therefore, we examined whether the downregulation of PERK and BiP was dependent on the SOX2 transcription factor or whether SOX2OT reduced the expression of these proteins independently of SOX2. In SOX2-overexpressing cells (Supplementary Materials Figure S2), when BiP, CHOP, and ATF4 were quantified at the mRNA level by RT-qPCR, ATF4 was slightly but significantly upregulated, compared to the control cells (Figure 6A) (Fold change $=1.32, p<0.001)$. 


\section{A}

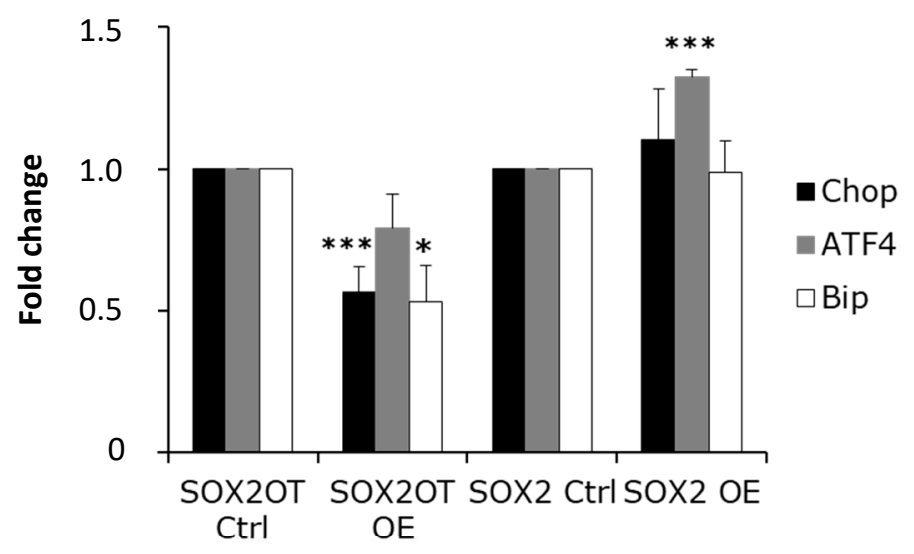

B

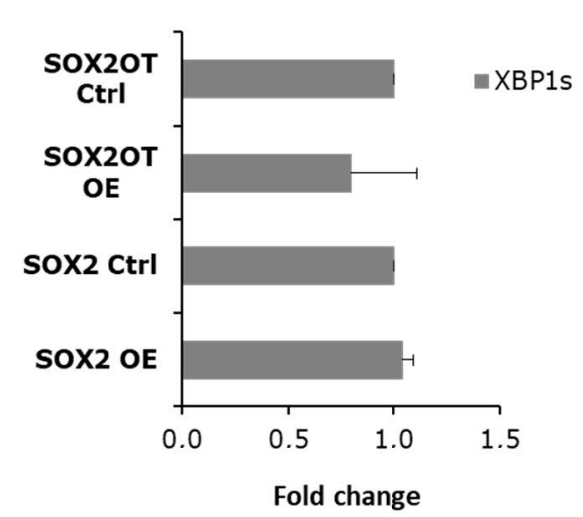

C

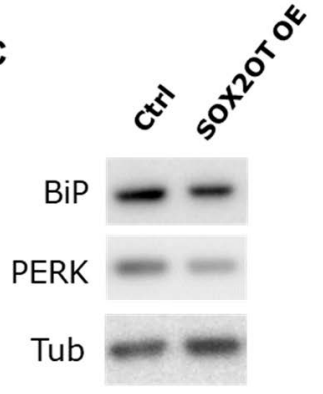

Figure 6. Effect of ectopic expression of SOX2OT or SOX2 on the UPR signalling pathway. MDA-MB231 cells were transfected with plasmids containing the SOX2OT gene (NR_004053.3) or the SOX2 gene (NM_003106), or with their respective control vectors. (A): Expression of BiP, ATF4, and CHOP relative to that of HPRT and GAPDH was measured by RT-qPCR. (B): Relative expression of XBP1s was measured by RT-qPCR relative to that of HPRT and GAPDH. (C): Protein expression levels of BiP and PERK were examined using Western Blot analysis. $\alpha$-tubulin was used as loading control. Error bars represent standard deviations of three independent clones. ${ }^{*} p<0.05,{ }^{* * *} p<0.001$.

\section{Discussion}

Since the discovery of the adaptive response to the disruption of endoplasmic reticulum homeostasis, the UPR has emerged as having a major role in modulating the expression of cancer-related genes, notably through transcriptional or post-transcriptional changes. Here, we describe a new layer of regulatory mechanisms of the UPR, affected by the lncRNA SOX2OT.

Thousands of lncRNAs have been identified in cancer cells [37], but very little is known about their functions and mechanisms of action. Their localisation in varying subcellular compartments (nucleus or cytoplasm), and their ability to bind to a variety of targets suggest that they should regulate gene expression and also have an effect on posttranscriptional regulation or structural interaction. SOX2OT was first described in 2009 [3], and little is known about its role and the regulation of its expression. SOX2OT is expressed in different cancers, including breast [4,38,39], oesophagus [6], and lung [7,9]. Its effect on proliferation depends on the cell line studied. In lung cancer, cell lines SOX2OT inhibits cell cycle progression by regulating the expression of the histone-lysine $\mathrm{N}$-methyltransferase enzyme EZH2 [7]. Conversely, in breast cancer cell lines, SOX2OT overexpression reduced proliferation and increased anchorage-independent growth [4]. 
In this study, we have shown that two ER-stress inducers - the decrease of glucose availability or the inhibition of the endoplasmic reticulum $\mathrm{Ca}^{2+}$-ATPase by $\mathrm{Tg}$ - induced the expression of SOX2OT. Everolimus and 4OH-Tam, two drugs that are used to treat breast cancer and are known to induce the UPR in breast cancer cell lines [21,40], also induced an upregulation of the SOX2OT transcript, suggesting that SOX2OT and the UPR are related. This was confirmed using the MDA-MB-231 TNBC (triple-negative breast cancer) cell line that has a very low expression of SOX2OT and a strong expression of BiP. Here, we have shown that the overexpression of SOX2OT downregulates BiP expression and PERK pathway activity.

SOX2 lies in an intron of the SOX2OT gene and is positively correlated with SOX2OT expression in breast cancer [4]. Therefore, SOX2OT is proposed to contribute to the transcriptional regulation of SOX2 [6,7]. We observed that when MCF-7 or T47D breast cancer cells were treated with 4OH-Tam, SOX2 expression and SOX2OT expression increased concordantly. However, SOX2 overexpression neither decreased BiP expression nor affected the PERK pathway. These results show that the effect of SOX2OT on BiP or PERK pathway (measured by ATF4 and CHOP RNA expression level) is independent of SOX2. Thus, SOX2OT has other targets yet to be identified. Furthermore, when the UPR was activated by $\mathrm{Tg}$ or glucose depletion, we observed that the correlation between SOX2 and SOX2OT abundance was lost, suggesting that other factors regulate SOX2 expression. This dissociation of SOX2OT and SOX2 expression is also observed in TNBCs that have downregulated SOX2OT but still expressed SOX2 [4]. Feng et al. [41] have demonstrated that in TBNC, cells that are prone to EMT have a high level of expression of BiP. This high expression may arise in part from SOX2OT downregulation and may promote the selection of more aggressive phenotypes or stem cell differentiation.

Other lncRNA molecules are known to be regulated by the UPR including MALAT1 [42]. Its splicing is enhanced by PERK during infection by flavivirus [41]. These results suggest that the activation of the PERK pathway enhances the translation of specific mRNAs or miRNA as well as the expression of lncRNAs. The analysis of TCGA breast cancer samples showed a positive correlation between XBP1 and SOX2OT, notably, in HER2 negative breast cancer samples (Supplementary Materials Table S2), suggesting that the IRE1 pathway could also regulate lncRNA.

Numerous studies have demonstrated that oestrogen deprivation induced a UPR [33-35]. In ER+ breast cancer cell lines, ER alpha-targeted therapy increased aggregation of ER alpha in the cytoplasm and increased UPR signalling [43]. The activation of UPR contributes to the development of resistance to oestrogen deprivation, as demonstrated by the overexpression of XBP1s [23] and BiP [44,45] or the activation of the PERK pathway [20,21,25]. Since SOX2OT is expressed early during UPR activation, it can participate in the reprogramming of gene expression by the UPR during the acute phase of oestrogen deprivation-mediated stress and lead to the emergence of resistant phenotypes. When treated with $4 \mathrm{OH}-\mathrm{Tam}$, MCF-7, T47D or TamC3 cells increased the expression of SOX2OT, whereas, in TamC6 cells, 4OH-Tam has no effect on SOX2OT expression, suggesting that in some resistant cell lines, upon chronic induction of the UPR, the mechanisms of regulation of SOX2OT expression are lost. The same observation was made following treatment with the mTOR inhibitor everolimus that has no effect on SOX2OT expression when cells are resistant to mTOR inhibition.

Together, our results show that long noncoding RNA can be considered a regulator of the UPR and provide evidence for a new function of SOX2OT as a participant of ENR stress reprogramming of breast cancer cells. Whether this LncRNA mediates its function through interactions with proteins, RNA, DNA, or a combination of these remains to be investigated. Therefore, overcoming SOX2OT overexpression and its effect on the PERK pathway or on SOX2 expression could result in the adaptation of the cells to ENR stress and consequently in the resistance to anti-oestrogen treatment and/or the promotion of EMT (Figure 7). Further investigations are needed to determine whether SOX2OT may provide a basis for new therapeutics to modify UPR in breast cancer. 


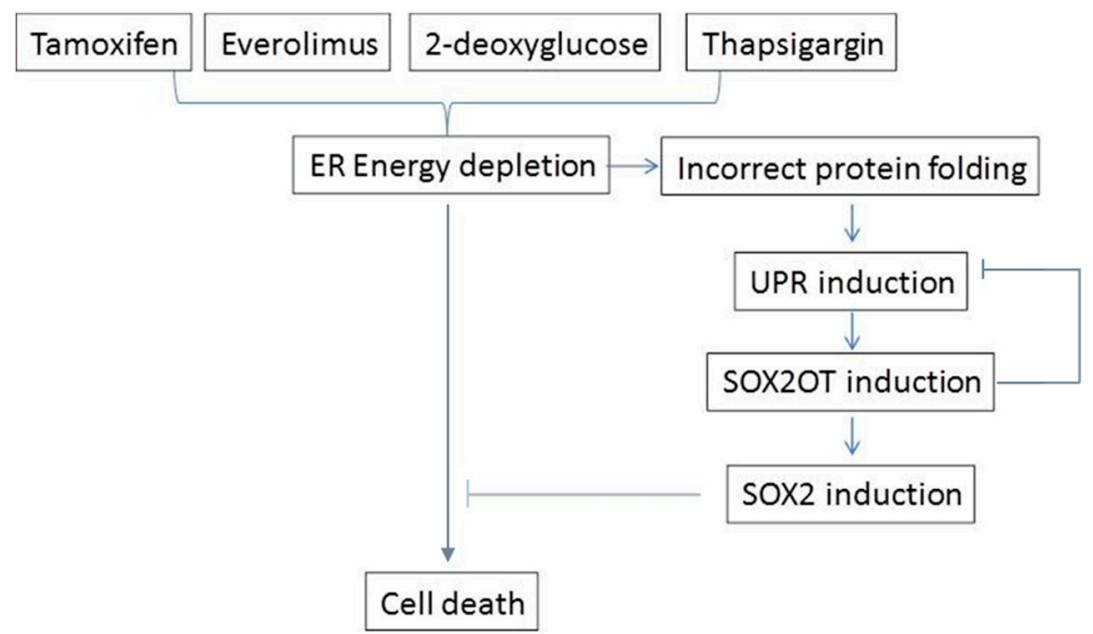

Figure 7. Hypothetical schema of SOX2OT lncRNA and UPR interrelation.

Supplementary Materials: The following are available online at https:/ /www.mdpi.com/article/10 .3390 / sci3020026/s1, Figure S1: Expression of SOX2OT lncRNA and SOX2 following UPR induction in ER+ breast cancer cell lines, Figure S2: Comparison of SOX2 expression in control and SOX2 overexpressing MDA-MB-231, Table S1: List of primers used in these experiments, Table S2: Spearman correlation coefficients of relative gene expression for SOX2OT compared to the expression of genes of the UPR pathways in TCGA Her2 neg/pos or Hormone neg/pos samples

Author Contributions: Conceptualization, C.F.-P., E.Y.L. and M.E.A.-A.; methodology, C.F.-P., D.S. and W.R.J.; software, C.F.-P. and H.H.; validation, E.Y.L. and M.E.A.-A.; formal analysis, C.F.-P. and D.S.; investigation, C.F.-P.; resources, E.Y.L. and M.E.A.-A.; data curation, C.F.-P.; writing-original draft preparation, C.F.-P., E.Y.L., M.E.A.-A. and B.C.B.; writing-review and editing, C.F.-P., E.Y.L.; visualization, all authors; supervision, B.C.B.; project administration, B.C.B..; funding acquisition, C.F.P., E.Y.L. and M.E.A.-A.; All authors have read and agreed to the published version of the manuscript.

Funding: C.F.-P. is supported by La Ligue Saône et Loire and the Hospices Civils de Lyon. M.E.A.-A. is supported by the Genesis Oncology Trust fund. E.Y.L. is supported by the NZ Breast cancer foundation.

Institutional Review Board Statement: Not applicable.

Informed Consent Statement: Not applicable.

Data Availability Statement: Data and materials are available on request from the corresponding authors.

Acknowledgments: We thank G.J. Finlay for his careful reading of the paper and the constructive comments he gave. C.F.-P. is supported by La Ligue Saône et Loire and the Hospices Civils de Lyon. M.E.A.-A. is supported by the Genesis Oncology Trust. E.Y.L. is supported by the NZ Breast Cancer Foundation.

Conflicts of Interest: The authors declare no conflict of interest.

\section{References}

1. Hansji, H.; Leung, E.Y.; Baguley, B.C.; Finlay, G.J.; Askarian-Amiri, M.E. Keeping abreast with long non-coding RNAs in mammary gland development and breast cancer. Front. Genet. 2014, 5, 379. [CrossRef] [PubMed]

2. Su, X.; Malouf, G.G.; Chen, Y.; Zhang, J.; Yao, H.; Valero, V.; Weinstein, J.N.; Spano, J.-P.; Meric-Bernstam, F.; Khayat, D.; et al. Comprehensive analysis of long non-coding RNAs in human breast cancer clinical subtypes. Oncotarget 2014, 5, 9864-9876. [CrossRef]

3. Youness, R.A.; Gad, M.Z. Long non-coding RNAs: Functional regulatory players in breast cancer. NonCoding RNA Res. 2019, 4, 36-44. [CrossRef] [PubMed]

4. Askarian-Amiri, M.E.; Seyfoddin, V.; Smart, C.E.; Wang, J.; Kim, J.E.; Hansji, H.; Baguley, B.C.; Finlay, G.J.; Leung, E.Y. Emerging Role of Long Non-Coding RNA SOX2OT in SOX2 Regulation in Breast Cancer. PLoS ONE 2014, 9, e102140. [CrossRef] [PubMed]

5. Amaral, P.P.; Neyt, C.; Wilkins, S.J.; Askarian-Amiri, M.E.; Sunkin, S.M.; Perkins, A.C.; Mattick, J.S. Complex architecture and regulated expression of the Sox2ot locus during vertebrate development. RNA 2009, 15, 2013-2027. [CrossRef] [PubMed] 
6. Shahryari, A.; Rafiee, M.R.; Fouani, Y.; Oliae, N.A.; Samaei, N.M.; Shafiee, M.; Semnani, S.; Vasei, M.; Mowla, S.J. Two novel splice variants of SOX2OT, SOX2OT-S1, and SOX2OT-S2 are coupregulated with SOX2 and OCT4 in esophageal squamous cell carcinoma. Stem Cells 2014, 32, 126-134. [CrossRef] [PubMed]

7. Hou, Z.; Zhao, W.; Zhou, J.; Shen, L.; Zhan, P.; Xu, C.; Chang, C.; Bi, H.; Zou, J.; Yao, X.; et al. A long noncoding RNA Sox2ot regulates lung cancer cell proliferation and is a prognostic indicator of poor survival. Int. J. Biochem. Cell Biol. 2014, 53, 380-388. [CrossRef]

8. Saghaeian Jazi, M.; Samaei, N.M.; Ghanei, M.; Shadmehr, M.B.; Mowla, S.J. Identification of new SOX2OT transcript variants highly expressed in human cancer cell lines and down regulated in stem cell differentiation. Mol. Biol. Rep. 2016, 43, 65-72. [CrossRef]

9. Saghaeian Jazi, M.; Samaei, N.M.; Ghanei, M.; Shadmehr, M.B.; Mowla, S.J. Overexpression of the non-coding SOX2OT variants 4 and 7 in lung tumors suggests an oncogenic role in lung cancer. Tumour Biol. 2016, 37, 10329-10338. [CrossRef]

10. Ron, D.; Walter, P. Signal integration in the endoplasmic reticulum unfolded protein response. Nat. Rev. Mol. Cell Biol. 2007, 8, 519-529. [CrossRef]

11. Ma, Y.; Hendershot, L.M. ER chaperone functions during normal and stress conditions. J. Chem. Neuroanat. 2004, $28,51-65$. [CrossRef]

12. Medigeshi, G.R.; Lancaster, A.M.; Hirsch, A.J.; Briese, T.; Lipkin, W.I.; DeFilippis, V.; Früh, K.; Mason, P.W.; Nikolich-Zugich, J.; Nelson, J.A. West Nile Virus Infection Activates the Unfolded Protein Response, Leading to CHOP Induction and Apoptosis. J. Virol. 2007, 81, 10849-10860. [CrossRef]

13. Andruska, N.; Zheng, X.; Yang, X.; Helferich, W.G.; Shapiro, D.J. Anticipatory estrogen activation of the unfolded protein response is linked to cell proliferation and poor survival in estrogen receptor $\alpha$-positive breast cancer. Oncogene 2015, 34, 3760-3769. [CrossRef] [PubMed]

14. Davies, M.P.A.; Barraclough, D.L.; Stewart, C.; Joyce, K.A.; Eccles, R.M.; Barraclough, R.; Rudland, P.S.; Sibson, D.R. Expression and splicing of the unfolded protein response gene XBP-1 are significantly associated with clinical outcome of endocrine-treated breast cancer. Int. J. Cancer 2008, 123, 85-88. [CrossRef]

15. Dong, D.; Ni, M.; Li, J.; Xiong, S.; Ye, W.; Virrey, J.J.; Mao, C.; Ye, R.; Wang, M.; Pen, L.; et al. Critical Role of the Stress Chaperone GRP78/BiP in Tumor Proliferation, Survival, and Tumor Angiogenesis in Transgene-Induced Mammary Tumor Development. Cancer Res. 2008, 68, 498-505. [CrossRef] [PubMed]

16. Livezey, M.; Kim, J.E.; Shapiro, D.J. A New Role for Estrogen Receptor $\alpha$ in Cell Proliferation and Cancer: Activating the Anticipatory Unfolded Protein Response. Front. Endocrinol. 2018, 9, 325. [CrossRef] [PubMed]

17. Cook, K.L.; Clarke, R. Role of GRP78 in promoting therapeutic-resistant breast cancer. Future Med. Chem. 2015, 7, 1529-1534. [CrossRef] [PubMed]

18. Fu, Y.; Li, J.; Lee, A.S. GRP78/BiP Inhibits Endoplasmic Reticulum BIK and Protects Human Breast Cancer Cells against Estrogen Starvation-Induced Apoptosis. Cancer Res. 2007, 67, 3734-3740. [CrossRef]

19. Zhou, H.; Zhang, Y.; Fu, Y.; Chan, L.; Lee, A.S. Novel Mechanism of Anti-apoptotic Function of 78-kDa Glucose-regulated Protein (GRP78) endocrine resistance factor in breast cancer, through release of b-cell lymphoma 2 (bcl-2) from bcl-2-interacting killer (BIK). J. Biol. Chem. 2011, 286, 25687-25696. [CrossRef]

20. Sengupta, S.; Sharma, C.G.N.; Jordan, V.C. Estrogen regulation of X-box binding protein-1 and its role in estrogen induced growth of breast and endometrial cancer cells. Horm. Mol. Biol. Clin. Investig. 2010, 2, 235-243. [CrossRef]

21. Gomez, B.P.; Riggins, R.B.; Shajahan, A.N.; Klimach, U.; Wang, A.; Crawford, A.C.; Zhu, Y.; Zwart, A.; Wang, M.; Clarke, R. Human X-box binding protein-1 confers both estrogen independence and antiestrogen resistance in breast cancer cell lines. FASEB J. 2007, 21, 4013-4027. [CrossRef]

22. Logue, S.E.; McGrath, E.P.; Cleary, P.; Greene, S.; Mnich, K.; Almanza, A.; Chevet, E.; Dwyer, R.M.; Oommen, A.; Legembre, P.; et al. Inhibition of IRE1 RNase activity modulates the tumor cell secretome and enhances response to chemotherapy. Nat. Commun. 2018, 9, 1-14. [CrossRef] [PubMed]

23. Ming, J.; Ruan, S.; Wang, M.; Ye, D.; Fan, N.; Meng, Q.; Tian, B.; Huang, T. A novel chemical, STF-083010, reverses tamoxifenrelated drug resistance in breast cancer by inhibiting IRE1/XBP1. Oncotarget 2015, 6, 40692-40703. [CrossRef]

24. Chen, X.; Iliopoulos, D.; Zhang, Q.; Tang, Q.; Greenblatt, M.B.; Hatziapostolou, M.; Lim, E.; Tam, W.L.; Ni, M.; Chen, Y.; et al. XBP1 promotes triple-negative breast cancer by controlling the HIF1 $\alpha$ pathway. Nature 2014, 508, 103-107. [CrossRef] [PubMed]

25. Del Vecchio, C.A.; Feng, Y.; Sokol, E.S.; Tillman, E.J.; Sanduja, S.; Reinhardt, F.; Gupta, P.B. De-differentiation confers multidrug resistance via noncanonical PERK-Nrf2 signaling. PLoS Biol. 2014, 12, e1001945. [CrossRef] [PubMed]

26. Hollien, J.; Weissman, J.S. Decay of endoplasmic reticulum-localized mRNAs during the unfolded protein response. Science 2006, 313, 104-107. [CrossRef] [PubMed]

27. Chevet, E.; Hetz, C.; Samali, A. Endoplasmic reticulum stress-activated cell reprogramming in oncogenesis. Cancer Discov. 2015, 5, 586-597. [CrossRef] [PubMed]

28. Leung, E.; Kannan, N.; Krissansen, G.W.; Findlay, M.P.; Baguley, B.C. MCF-7 breast cancer cells selected for tamoxifen resistance acquire new phenotypes differing in DNA content, phospho-HER2 and PAX2 expression, and rapamycin sensitivity. Cancer Biol. Ther. 2010, 9, 717-724. [CrossRef] [PubMed]

29. Leung, E.; Kim, J.E.; Askarian-Amiri, M.; Finlay, G.J.; Baguley, B.C. Evidence for the existence of triple-negative variants in the MCF-7 breast cancer cell population. Biomed. Res. Int. 2014, 2014, 836769. [CrossRef] 
30. Leung, E.Y.; Kim, J.E.; Askarian-Amiri, M.; Joseph, W.R.; McKeage, M.J.; Baguley, B.C. Hormone Resistance in Two MCF-7 Breast Cancer Cell Lines is Associated with Reduced mTOR Signaling, Decreased Glycolysis, and Increased Sensitivity to Cytotoxic Drugs. Front. Oncol. 2014, 4, 221. [CrossRef]

31. Leung, E.Y.; Askarian-Amiri, M.; Finlay, G.J.; Rewcastle, G.W.; Baguley, B.C. Potentiation of Growth Inhibitory Responses of the mTOR Inhibitor Everolimus by Dual mTORC1/2 Inhibitors in Cultured Breast Cancer Cell Lines. PLoS ONE 2015, 10, e0131400. [CrossRef]

32. Leung, E.Y.; Askarian-Amiri, M.E.; Sarkar, D.; Ferraro-Peyret, C.; Joseph, W.R.; Finlay, G.J.; Baguley, B.C. Endocrine Therapy of Estrogen Receptor-Positive Breast Cancer Cells: Early Differential Effects on Stem Cell Markers. Front. Oncol. 2017, 7, 184. [CrossRef]

33. Andres, S.A.; Wittliff, J.L. Relationships of ESR1 and XBP1 expression in human breast carcinoma and stromal cells isolated by laser capture microdissection compared to intact breast cancer tissue. Endocrine 2011, 40, 212-221. [CrossRef] [PubMed]

34. Raina, K.; Noblin, D.J.; Serebrenik, Y.V.; Adams, A.; Zhao, C.; Crews, C.M. Targeted protein destabilization reveals an estrogenmediated ER stress response. Nat. Chem. Biol. 2014, 10, 957-962. [CrossRef]

35. Scriven, P.; Coulson, S.; Haines, R.; Balasubramanian, S.; Cross, S.; Wyld, L. Activation and clinical significance of the unfolded protein response in breast cancer. Br. J. Cancer 2009, 101, 1692-1698. [CrossRef]

36. Cook, K.L.; Soto-Pantoja, D.R.; Clarke, P.A.G.; Cruz, M.I.; Zwart, A.; Wärri, A.; Hilakivi-Clarke, L.; Roberts, D.D.; Clarke, R. Endoplasmic Reticulum Stress Protein GRP78 Modulates Lipid Metabolism to Control Drug Sensitivity and Antitumor Immunity in Breast Cancer. Cancer Res. 2016, 76, 5657-5670. [CrossRef]

37. Chen, Q.; Wei, C.; Wang, Z.; Sun, M. Long non-coding RNAs in anti-cancer drug resistance. Oncotarget 2016, 8, 1925-1936. [CrossRef] [PubMed]

38. Iranpour, M.; Soudyab, M.; Geranpayeh, L.; Mirfakhraie, R.; Azargashb, E.; Movafagh, A.; Ghafouri-Fard, S. Expression analysis of four long noncoding RNAs in breast cancer. Tumour Biol. 2016, 37, 2933-2940. [CrossRef]

39. Tang, X.; Gao, Y.; Yu, L.; Lu, Y.; Zhou, G.; Cheng, L.; Sun, K.; Zhu, B.; Xu, M.; Liu, J. Correlations between lncRNA-SOX2OT polymorphism and susceptibility to breast cancer in a Chinese population. Biomark. Med. 2017, 11, 277-284. [CrossRef]

40. Martín-Pérez, R.; Palacios, C.; Yerbes, R.; Cano-González, A.; Iglesias-Serret, D.; Gil, J.; Reginato, M.J.; López-Rivas, A. Activated ERBB2/HER2 licenses sensitivity to apoptosis upon endoplasmic reticulum stress through a PERK-dependent pathway. Cancer Res. 2014, 74, 1766-1777. [CrossRef] [PubMed]

41. Feng, Y.-X.; Sokol, E.S.; Del Vecchio, C.A.; Sanduja, S.; Claessen, J.H.L.; Proia, T.A.; Jin, D.X.; Reinhardt, F.; Ploegh, H.L.; Wang, Q.; et al. Epithelial-to-mesenchymal transition activates PERK-eIF2 $\alpha$ and sensitizes cells to endoplasmic reticulum stress. Cancer Discov. 2014, 4, 702-715. [CrossRef] [PubMed]

42. Quan, H.; Fan, Q.; Li, C.; Wang, Y.-Y.; Wang, L. The transcriptional profiles and functional implications of long non-coding RNAs in the unfolded protein response. Sci. Rep. 2018, 8, 4981. [CrossRef] [PubMed]

43. Clarke, R.; Shajahan, A.N.; Wang, Y.; Tyson, J.J.; Riggins, R.B.; Weiner, L.M.; Bauman, W.T.; Xuan, J.; Zhang, B.; Facey, C.; et al. Endoplasmic reticulum stress, the unfolded protein response, and gene network modeling in antiestrogen resistant breast cancer. Horm. Mol. Biol. Clin. Investig. 2011, 5, 35-44. [CrossRef] [PubMed]

44. Clarke, R.; Cook, K.L.; Hu, R.; Facey, C.O.B.; Tavassoly, I.; Schwartz, J.L.; Baumann, W.T.; Tyson, J.J.; Xuan, J.; Wang, Y.; et al. Endoplasmic reticulum stress, the unfolded protein response, autophagy, and the integrated regulation of breast cancer cell fate. Cancer Res. 2012, 72, 1321-1331. [CrossRef]

45. Cook, K.L.; Clarke, R. Heat shock $70 \mathrm{kDa}$ protein 5/glucose-regulated protein 78 "AMP” ing up autophagy. Autophagy 2012, 8, 1827-1829. [CrossRef] 